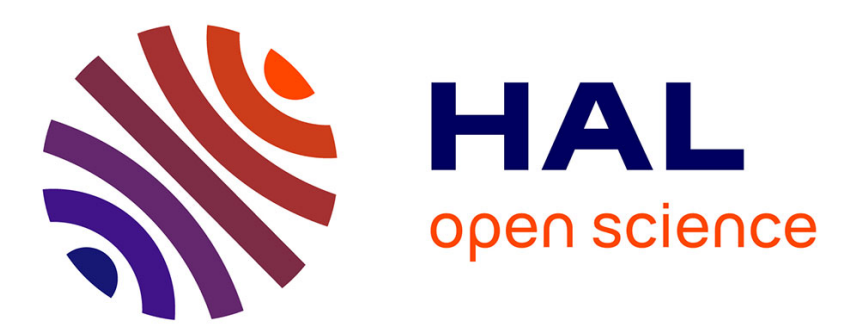

\title{
Study of cystic fibrosis patient skills acquisition using a pedagogical evaluation system
}

Claire Marchand, Anne Jolivet, Jacqueline Iguenane, Valérie David, Colette Berville, Marythé Kerbrat, Rémi Gagnayre

\section{- To cite this version:}

Claire Marchand, Anne Jolivet, Jacqueline Iguenane, Valérie David, Colette Berville, et al.. Study of cystic fibrosis patient skills acquisition using a pedagogical evaluation system. Éducation thérapeutique du patient / Therapeutic patient education , 2011, 3 (1), pp.35-44. 10.1051/tpe/2011106 . hal-01680947

\section{HAL Id: hal-01680947 https://sorbonne-paris-nord.hal.science/hal-01680947}

Submitted on 17 Jan 2018

HAL is a multi-disciplinary open access archive for the deposit and dissemination of scientific research documents, whether they are published or not. The documents may come from teaching and research institutions in France or abroad, or from public or private research centers.
L'archive ouverte pluridisciplinaire HAL, est destinée au dépôt et à la diffusion de documents scientifiques de niveau recherche, publiés ou non, émanant des établissements d'enseignement et de recherche français ou étrangers, des laboratoires publics ou privés. 


\title{
Article original/Original article
}

\section{Study of cystic fibrosis patient skills acquisition using a pedagogical evaluation system}

\author{
Claire Marchand ${ }^{1 \star}$, Anne Jolivet $^{1}$, Jacqueline Iguenane $^{1}$, Valérie David ${ }^{2}$, Colette Berville $^{2}$, \\ Marythé Kerbrat ${ }^{3}$, Rémi Gagnayre ${ }^{1}$ \\ 1 Health Education Laboratory, EA-3412, University Paris 13, Bobigny, France \\ 2 Cystic fribrosis reference center, CHU Nantes, France \\ 3 Cystic fibrosis reference center, Roscoff, France
}

(Received 13 March 2011, accepted 3 May 2011)

\begin{abstract}
Introduction: We developed a pedagogical evaluation system for assessing patient skills in the context of therapeutic patient education (TPE). Objectives: To use the pedagogical evaluation system to show how patient skills change at different points in their education program, and to investigate correlations between the different skills assessed. Methods: Forty-eight cystic fibrosis patients performed three evaluations each. A total of 144 evaluations were analyzed using statistical tests. Results: In general, patients' skill assessment scores tended to go up over time. We found stable associations among the different self-care skills and between self-care and metacognitive skills, and less stable associations among the different adaptation to illness skills. The study failed to show any correlation between self-care skills and adaptation to illness skills. Conclusion: Improvements are suggested to increase the quality of the pedagogical evaluation system, the foremost being that all the different skills should be assessed using the same problem situation.
\end{abstract}

Key words: evaluation / skill / cystic fibrosis / self-care / adaptation to illness

Résumé - Étude des acquisitions de compétences de patients atteints de mucoviscidose au moyen d'un dispositif d'évaluation pédagogique. Introduction : Dans le cadre de l'ETP un dispositif d'évaluation des compétences du patient a été élaboré. Objectifs : Montrer à l'aide du dispositif, l'évolution des compétences des patients à différents temps de leur suivi éducatif, et étudier l'existence de corrélations entre les différentes compétences évaluées. Méthodes : Quarante-huit patients atteints de mucoviscidose ont réalisé 3 évaluations chacun. Un total de 144 évaluations a été analysé à l'aide de tests statistiques. Résultats D'une manière générale, les scores obtenus par les patients à l'évaluation de leurs compétences ont tendance à augmenter. Des associations stables sont retrouvées concernant des compétences d'auto-soins, des compétences d'auto-soins et métacognitives, et de façon moins stable des compétences d'adaptation à la maladie entre-elles. Cette étude n'a pas mis en évidence de corrélation entre des compétences d'auto-soins et celles d'adaptation à la maladie. Conclusion : Des propositions sont faites afin d'améliorer la qualité du dispositif : il s'agit principalement d'évaluer les différentes compétences à partir d'une même situation-problème.

Mots clés : évaluation pédagogique / compétence / mucoviscidose / auto-soins / adaptation à la maladie

\section{Introduction}

It is recognized in the field of patient education that patients call upon a large number of skills in managing their illness, its treatment, and the attendant personal, family and social impacts. Since the publication of the HAS-INPES rec-

\footnotetext{
^ Correspondence:

Health Education Laboratory, EA-3412, University Paris 13, 74 rue Marcel Cachin, 93019, Bobigny Cedex, France, claire.marchand@univ-paris13.fr
}

ommendations, these skills have been known as self-care and adaptation to illness [1]. In the case of cystic fibrosis, patients must call upon several skills in any given day: identifying high fat foods and adjusting their pancreatic enzyme dose, recognizing the warning signs of a flare-up, and performing technical procedures such as inhaler use and kinesitherapy exercises several times a day [2]. In order to acquire and maintain these skills, patients can participate to therapeutic education program and pedagogical evaluation to identify their strengths and weaknesses in applying these skills on a daily basis. 
In a previous paper we proposed a pedagogical evaluation system for assessing skills acquisition in cystic fibrosis patients [3]. The choice of skills assessed by this pedagogical evaluation system is based on an analysis of the literature, where dependence between some skills has been reported. In the general health care field, one study has demonstrated possible links between self-care and self-concept [4]. In the field of cystic fibrosis therapeutic patient education, mastery of adaptation to illness skills has been shown to influence the mastery of self-care skills such as problem solving, improving selfmanagement behavior for cystic fibrosis. [5]. On the basis of these findings, we decided to combine the following skills into a single pedagogical evaluation system: self-care skills, adaptation to illness skills, and metacognitive skills. Metacognitive skills, like self-assessment and thinking ahead, are essential to maintaining acquisitions over time [6]. The components of our pedagogical evaluation system are shown in Table I. First, we studied the consequential validity [7] of the pedagogical evaluation system using the perception of its usefulness by patients and caregivers as the outcome measure [8]. The results of that exploratory study demonstrate that as long as certain conditions for its use are met, such a pedagogical evaluation system is useful to both patients and healthcare professionals, helping to structure the evaluation interview by giving the patient an active role in his own evaluation. The pedagogical evaluation system proved useful in making patients aware of the skills acquired, helping them identify new educational needs, and encouraging them to discuss the objectives and contents of the education program with their healthcare professionals [8]. The assessed skills relate to different learning areas, such as perception, performance, planning, and problem solving. Independent of whether they are perceived as useful by users, this paper has two objectives: first, to use the pedagogical evaluation system to show how patient skills change at different points in their education program, and second, to investigate correlations between the different skills being assessed as described by different studies.

\section{Methods}

\subsection{Study procedure and data collection methods}

The pedagogical evaluation system was used in two cystic fibrosis centers, which have been developing patient education programs for several years. To apply the pedagogical evaluation system, volunteer health care professionals with at least two years of experience in cystic fibrosis and TPE training were given special preparation in the use of the pedagogical evaluation system, on adapting evaluation tools to cystic fibrosis skills, and on using the pedagogical evaluation system [8].

The study took place from September 2007 through June 2009, and involved 48 cystic fibrosis patients and seven caregiver-educators. Each patient was evaluated on three occasions, three months apart, on all of the skills considered in the pedagogical evaluation system. The same methodology was used for each evaluation: explanation of the evaluation process to the patient, evaluation of each skill in the order chosen by the patient, transfer of results to the display scale (Fig. 1), and discussion with the patient in order to make decisions regarding his education program [8]. At the end of each evaluation, the patient's results were placed in a patient file containing patient information (identity, health status, etc.), as well as the degree of mastery of the assessed skills. A skill-specific score was given for each skill assessed (Tab. I).

\subsection{Analysis methods}

First, we described the scores obtained for each skill at each of the three evaluations. In order to measure change over time, we compared the scores obtained at the first and second evaluations, and then at the second and third evaluations, using the Wilcoxon test.

Next, we looked for possible associations between the scores for each skill and individual patient characteristics specifically, age, sex, education level, socioprofessional classification (INSEE classification) and illness severity (as represented by the FEV1, or forced expiratory volume in one second). For this we used the Mann-Whitney test (for comparing two independent categories of patients) and the Kruskal-Wallis test (for comparing more than two independent categories of patients).

In the third and final step, we measured correlations between each pair of skills. The degree of association between skill pairs was analyzed using Spearman's correlation coefficient. This test is appropriate when the variable is not normally distributed. Its value ranges between -1 and +1 . A positive value indicates simultaneous variation in the same direction, a negative value simultaneous variation in the opposite direction. The closer to 1 the absolute value, the stronger the association. The associated test for significance allows us to test the strength of the association between the two variables.

The Spearman coefficient was calculated for each of the three evaluations (for each skill pair). When the correlation coefficient between two skills was significant for all three evaluations, we considered the association between those skills stable. Stability over time can be thought of as a reliability criterion for the associations found.

All the statistical tests used were non-parametric, due to the small sample size and to the asymmetric distribution of the skill scores. The significance threshold for the tests was 5\%. The software used was STATA version 10.0.

\section{Results}

\subsection{Description of the study sample}

A total of 48 patients ( 30 men and 18 women) participated in the study. All of them performed all three evaluations, for a total of 144 evaluations. The mean patient age was 24 years and $40 \%$ were students (Tab. II). 
Table I. Components of the pedagogical evaluation system [3]. - Composantes du dispositif d'évaluation pédagogique.

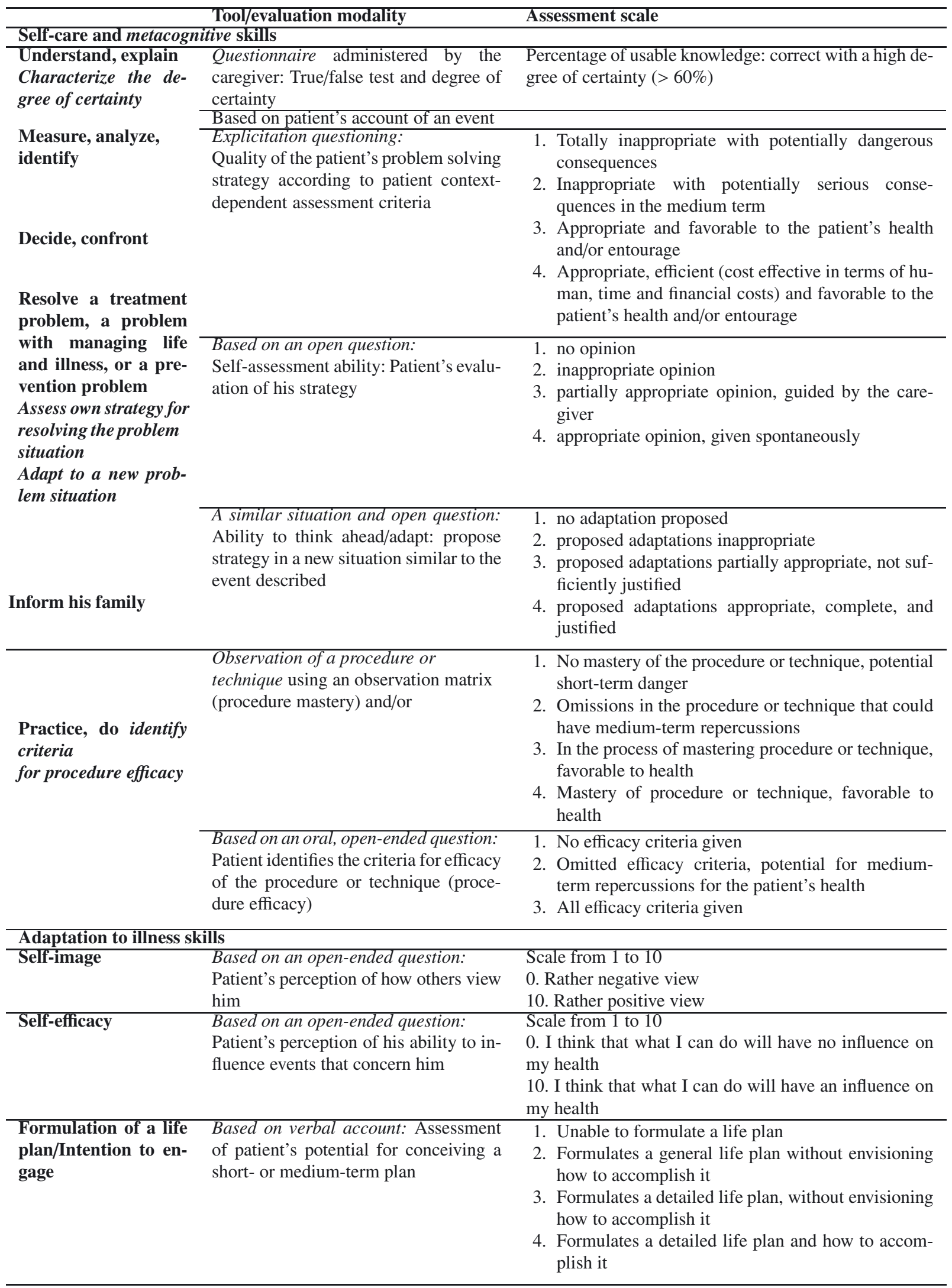




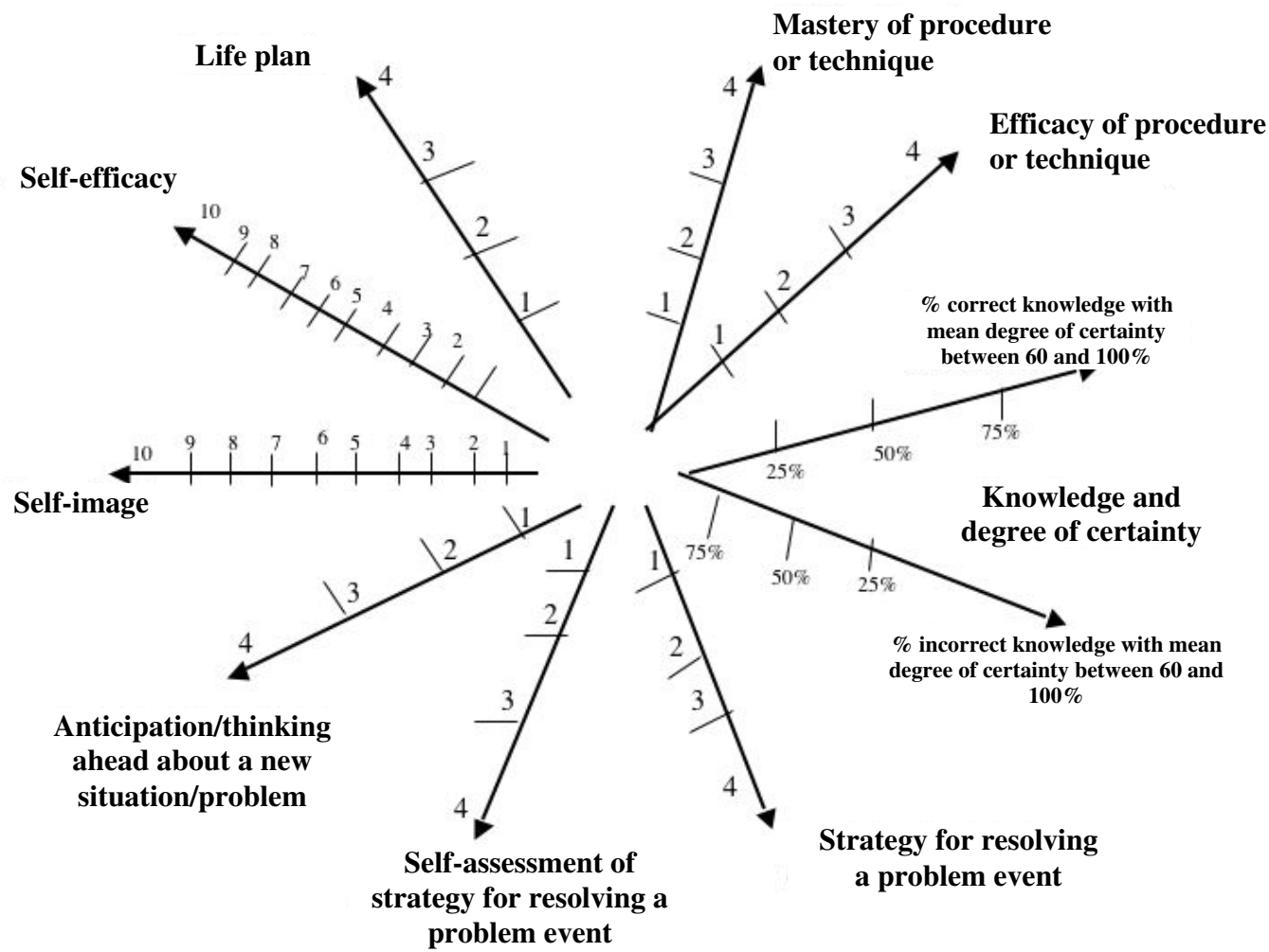

Figure 1. Display scale for presenting evaluation results. - Support de présentation des résultats de l'évaluation.

Table II. Description of the sample population. - Description de l'échantillon de population.

\begin{tabular}{lccccc}
\hline & $N$ & $\%$ & Min & Max & Mean \pm s.d. \\
\hline Sex & & & & & \\
- Female & 18 & 37.5 & & & \\
- Male & 30 & 62.5 & & & \\
Age & 48 & & 16 & 43 & $24.9 \pm 7.2$ \\
& & & & & \\
Education level & & & & & \\
- secondary school & 9 & 18.8 & & & \\
- high school & 19 & 39.6 & & & \\
- college & 10 & 20.8 & & & \\
- Bachelor's degree or higher & 10 & 20.8 & & & \\
& & & & & \\
Socioprofessional category & & & & & \\
- Student & 19 & 39.6 & & & \\
- Executive, interm. profession & 10 & 20.8 & & & \\
- Employee, worker, farmer & 14 & 29.2 & & & \\
- Other (inactive) & 5 & 10.4 & & & \\
& & & & & \\
FEV1 (\% theoretical value) & 46 & & 21 & 104.7 & $59.4 \pm 21.6$ \\
\hline
\end{tabular}


Table III. Scores for the three evaluations and analysis of change. - Valeurs accordées aux compétences aux 3 temps de l'évaluation et analyse de leur évolution.

\begin{tabular}{|c|c|c|c|c|c|c|}
\hline & $N$ & Min & Max & $\begin{array}{l}\text { Mean } \\
\pm \text { s.d. }\end{array}$ & $\begin{array}{c}\text { Change from } \\
t 1 \text { to } t 2(p *)\end{array}$ & $\begin{array}{c}\text { Change from } \\
t 2 \text { to } t 3(p *)\end{array}$ \\
\hline \multicolumn{7}{|l|}{ Procedure mastery } \\
\hline - Evaluation $1(\mathrm{t} 1)$ & 48 & 2 & 4 & $3.62 \pm 0.61$ & 0.56 & 0.96 \\
\hline - Evaluation 2 (t2) & 48 & 3 & 4 & $3.73 \pm 0.45$ & & \\
\hline - Evaluation 3 (t3) & 48 & 2 & 4 & $3.71 \pm 0.50$ & & \\
\hline \multicolumn{7}{|l|}{ Procedure efficacy } \\
\hline - Evaluation 1 & 47 & 2 & 4 & $3.53 \pm 0.55$ & 0.48 & 0.65 \\
\hline - Evaluation 2 & 48 & 3 & 4 & $3.62 \pm 0.49$ & & \\
\hline - Evaluation 3 & 48 & 2 & 4 & $3.56 \pm 0.62$ & & \\
\hline \multicolumn{7}{|l|}{ Usable knowledge } \\
\hline - Evaluation 1 & 48 & 40 & 95 & $74.11 \pm 12.94$ & $p<10^{-3}$ & $p<10^{-3}$ \\
\hline - Evaluation 2 & 48 & 52.5 & 100 & $86.77 \pm 10.94$ & & \\
\hline - Evaluation 3 & 48 & 57.5 & 100 & $92.92 \pm 8.76$ & & \\
\hline \multicolumn{7}{|c|}{ Dangerous knowledge } \\
\hline - Evaluation 1 & 48 & 0 & 17.5 & $5.78 \pm 3.72$ & 0.89 & 0.002 \\
\hline - Evaluation 2 & 48 & 0 & 15 & $5.73 \pm 3.89$ & & \\
\hline - Evaluation 3 & 48 & 0 & 15 & $3.85 \pm 3.68$ & & \\
\hline \multicolumn{7}{|l|}{ Problem solving } \\
\hline - Evaluation 1 & 48 & 1 & 4 & $3.25 \pm 0.79$ & 0.01 & 0.10 \\
\hline - Evaluation 2 & 48 & 2 & 4 & $3.54 \pm 0.62$ & & \\
\hline - Evaluation 3 & 48 & 2 & 4 & $3.69 \pm 0.62$ & & \\
\hline \multicolumn{7}{|l|}{ Self-assessment } \\
\hline - Assessment 1 & 48 & 2 & 4 & $3.58 \pm 0.65$ & 0.54 & 0.02 \\
\hline - Evaluation 2 & 48 & 2 & 4 & $3.65 \pm 0.56$ & & \\
\hline - Evaluation 3 & 48 & 3 & 4 & $3.85 \pm 0.36$ & & \\
\hline \multicolumn{7}{|l|}{ Thinking ahead } \\
\hline - Evaluation 1 & 48 & 2 & 4 & $3.60 \pm 0.57$ & 0.17 & 0.71 \\
\hline - Evaluation 2 & 48 & 2 & 4 & $3.73 \pm 0.49$ & & \\
\hline - Evaluation 3 & 48 & 1 & 4 & $3.71 \pm 0.71$ & & \\
\hline \multicolumn{7}{|l|}{ Self-image } \\
\hline - Evaluation 1 & 48 & 2 & 10 & $8.44 \pm 1.53$ & 0.17 & 0.01 \\
\hline - Evaluation 2 & 48 & 5 & 10 & $8.71 \pm 1.20$ & & \\
\hline - Evaluation 3 & 48 & 5 & 10 & $8.98 \pm 1.12$ & & \\
\hline \multicolumn{7}{|l|}{ Self-efficacy } \\
\hline - Evaluation 1 & 48 & 5 & 10 & $8.52 \pm 1.43$ & 0.56 & 0.01 \\
\hline - Evaluation 2 & 48 & 1 & 10 & $8.25 \pm 1.94$ & & \\
\hline - Evaluation 3 & 48 & 2 & 10 & $8.71 \pm 2.59$ & & \\
\hline \multicolumn{7}{|l|}{ Life plan } \\
\hline - Evaluation 1 & 48 & 1 & 4 & $3.67 \pm 0.69$ & 0.31 & 0.20 \\
\hline - Evaluation 2 & 47 & 1 & 4 & $3.77 \pm 0.56$ & & \\
\hline - Evaluation 3 & 48 & 3 & 4 & $3.87 \pm 0.33$ & & \\
\hline
\end{tabular}

$* p=$ significance level on the Wilcoxon test $(0,05)$.

\subsection{Description of the scores and change over time}

As Table III shows, the initial skill values were high. The trend in terms of acquisition was fairly good, though the change was not always statistically significant and varied over time. There was a statistically significant increase in problem solving score between the first and second evaluations. Other skills showed a statistically significant change between the second and third evaluations; there was improvement in self-assessment, self-image, and self-efficacy scores, and a decrease in the dangerous knowledge score (incorrect knowledge with a high degree of certainty) $[9,10]$. There was a steady in- crease in the usable knowledge score (correct knowledge with a high degree of certainty) [10] over the three evaluations; this improvement was more marked than that of other skills $(p<0.001)$.

\subsection{Associations between skills and individual patient characteristics}

There were few statistically significant associations found between the skill scores on the first evaluation and individual patient characteristics. The percentage of usable knowledge 
was higher for the oldest patients, patients with a higher level of education, and for executives and intermediate professions. The self-assessment level was higher for executives and intermediate professions, and lower for students. The ability to think ahead was higher for the bottom third of patients ranked by FEV1 score (forced expiratory volume in one second).

\subsection{Associations between skill pairs}

Table IV shows the matrix of Spearman correlation coefficients. Associations for five skill pairs meet the criterion for stability over time (statistically significant association between two skills at all three evaluations). These were:

- Level of procedure mastery and level of procedure efficacy;

- Percentage of usable knowledge and percentage of dangerous knowledge (inverse relationship);

- Problem solving skill and self-assessment ability;

- Problem solving skill and ability to think ahead;

- Self-assessment skill and ability to think ahead.

Associations for four other skill pairs partially meet the criterion for stability over time (statistically significant association between the skill pair on two out of three evaluations). These were:

- Percentage of correct knowledge and ability to think ahead;

- Self-image and sense of self-efficacy;

- Self-image and life plan.

\section{Discussion}

\subsection{Change in patient skills over time}

On average, patients' performance was high right from the start of the study, as shown in other studies [11]. This is explained, in part, by the fact that these patients have been followed for their disease since childhood [12]. They have developed knowledge and skills through experience, by participating in patient education sessions, and by their many contacts with the medical team. Moreover, the conditions in which the evaluations were done limited the factors that might impact patient performance, namely the absence of any stress in connection with the consequences of the evaluation, the patient-caregiver trust relationship, sufficient time allowed for answering, immediate feedback, etc. Overall, patient skills improved. However, the change varied from one skill to another and from one evaluation to another. We note that some adaptation to illness skills and dangerous knowledge (incorrect knowledge about which the patient expressed a high degree of certainty) showed particular improvement over time. These results demonstrate that patients did learn. There was a steady gain in usable knowledge over the three evaluations. This might be explained by the fact that as the patients became accustomed to the test, they remembered the answers, and that the majority of current TPE programs focus on knowledge acquisition.

\subsection{Correlations between skills}

This study failed to show any correlations between selfcare skills and adaptation to illness skills. It did, however, find associations among different self-care skills and between self-care and metacognitive skills, and less stable associations among the different adaptation to illness skills.

\subsection{Correlation between self-care skills and metacognitive skills}

The correlations between self-care and metacognitive skills most often reflect the way in which these skills were investigated, and thus the technique and tools employed by the pedagogical evaluation system itself.

Indeed, the self-assessment and thinking ahead skills (metacognitive skills) were evaluated directly using a single problem situation, whose solution strategy was described by the patient (self-care skill). The patient was then asked to assess his problem-solving strategy (self-assessment skill), and then to anticipate how to deal with the same type of situation in a slightly different context (ability to think ahead). These metacognitive skills are inevitably tied to the strategy and the context in which it is carried out [13]. There is, therefore, a reciprocal influence between these different skills, as pointed out by other authors [6]. This highlights the potential value of reinforcing these metacognitive skills in patient education, in order to maintain and improve patient self-care. It can be hypothesized that the better the patient is at resolving the problem situation, the better his ability to self-assess and the better his ability to anticipate how to handle new problems. The population being investigated must, however, be considered when discussing these results. Indeed, the patients in our study know a lot of things about their disease. They have been treated for many years, getting regular feedback from both health care professionals and their family. As a result, they have acquired a lot of knowledge, skills and experience. In addition, their problemsolving score is generally high on all three evaluations (above 3 out of 4, on average). Four patients showed an inconsistency between their problem solving and self-assessment skills. These patients incorrectly resolved their problem situation (score $=1$ or 2 ), but were aware of it, since their view of their problem solving strategy was considered fairly satisfactory (score $=3$ or 4 ). The self-assessment skill evaluated by this pedagogical evaluation system may be associated with one of the stages of reflective practice described by Schön [14]. It refers to a conscious, analytical evaluation of the effects of one's actions, in retrospect, and to an interpretation of the causes and consequences of those effects [15]. Such analysis calls directly upon the knowledge and skills acquired by the patient, as well as the criteria he uses to evaluate his actions. Thus, in a given context a skilled patient may act in a way that is inappropriate to his health situation, usually by reasoned choice, while his expertise in the area allows him an appropriately critical view of those actions after the fact. Interpreting the results of these evaluations thus requires that patients explain the reasoning they used when solving problems. 


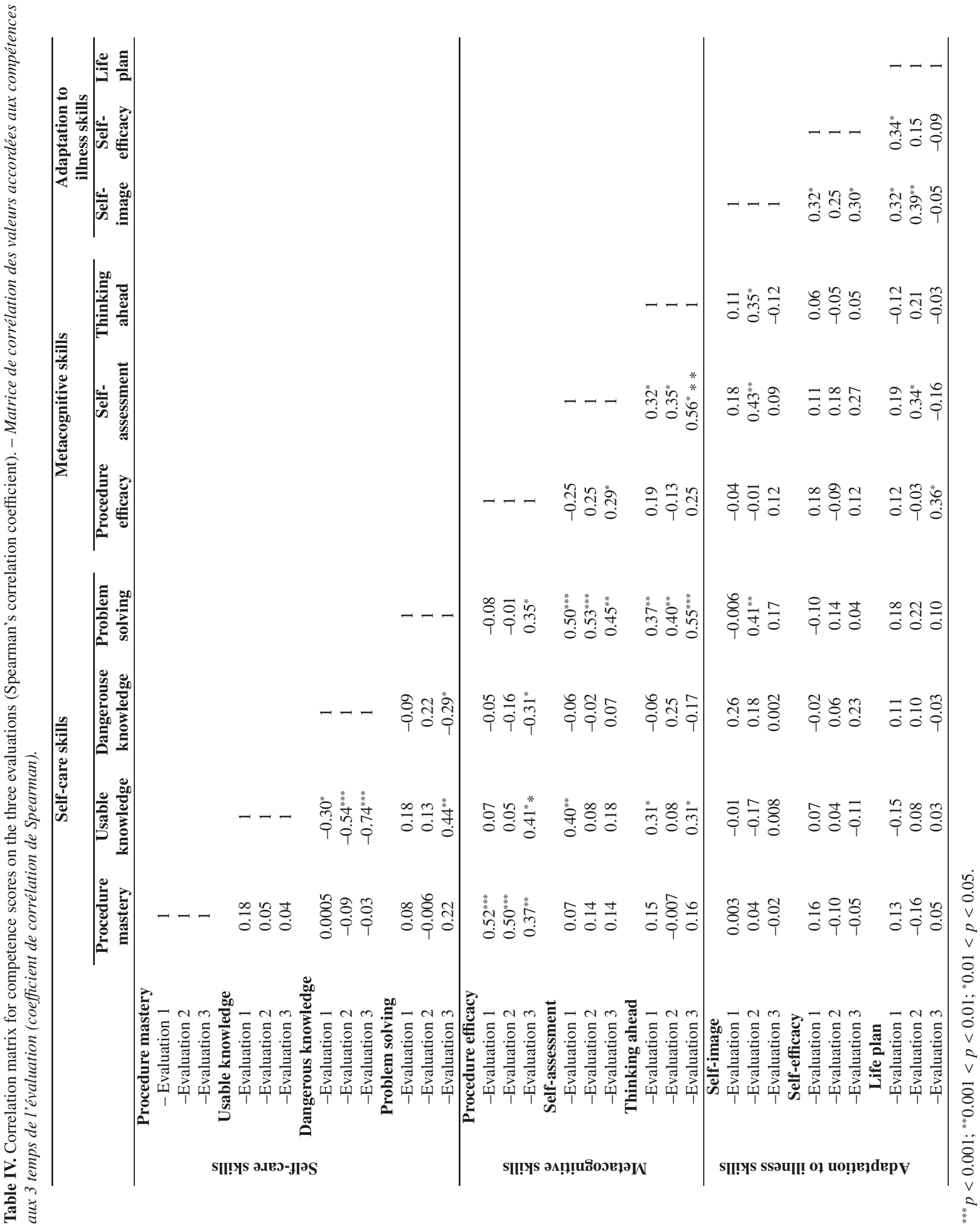


Regarding the evaluation of the patient's mastery of technical procedures, we see a correlation between the level of procedure mastery (self-care skill) and the ability to explain procedure efficacy (metacognitive skill). Thus two steps were routinely used to assess that skill. In the first, the patient demonstrated his technical mastery of the procedure. When the patient was unable perform the procedure due to a lack of equipment in the health care unit, for example, he was asked to describe the procedure, thus calling upon his knowledge of the steps of the procedure (declarative knowledge). No matter how it was done, the patient then had to state what, according to him, were the criteria he considered essential for the procedure to be effective. The evaluation for these two phases was based on the elements of the procedure observation matrix. The results show good correlation between these two evaluations, and confirm the value of teaching the patient how to perform the procedure and how to identify the criteria for its efficacy simultaneously.

\subsection{Correlation between self-care skills and adaptation to illness skills}

The lack of correlation between self-care and adaptation to illness skills in our study is significant. Yet the relationship between the patient's self-image or self-esteem, his sense of personal efficacy, and his ability to take care of himself have been demonstrated both in healthy adolescents [4] and in patients with Type I diabetes [16]. One hypothesis that might explain the lack of correlation between these skills in our study has to do with the situation upon which evaluation of adaptation to illness was based. Self-image and self-efficacy were assessed first by asking the patient to rate himself, generally, between two extremes, namely his positive or negative perception of how others see him, and then by asking for his perception of the influence, or lack thereof, of his actions (in general) on his health. With cystic fibrosis, one might assume - when explored in a general way - that patients would have a poor sense of self-efficacy, given the unfair nature of the disease, which inevitably progresses toward a deterioration in general health. Yet the scores for this skill were relatively high (Tab. III). A next study should allow us to verify the degree to which these two skills are correlated to the other skills when tested using the same problem situation [17]. For a cystic fibrosis patient, for example, we might assess his ability to adjust his pancreatic enzyme dose for a given problem situation, and then ask him to talk about his sense of self-efficacy with regard to his strategy. Another possible explanation for the lack of correlation might have to do with a measurement effect. The assessment scales offer only a small measurement range, while the scores are, on the whole, high. Since we are dealing with experienced patients, this is the most limiting factor in the statistical analysis.

It would be useful to do another study with less experienced patients, in order to get a more refined evaluation of the pedagogical evaluation system's potential for measuring the change in a patient's skills over the course of his education. With cystic fibrosis, where learning starts very young, it would be necessary to design a pedagogical evaluation system that takes into account the different developmental stages in childhood and adolescence [18].

\subsection{Prospects for improving the pedagogical evaluation system}

As the pedagogical evaluation system's usefulness to patients and healthcare professionals was demonstrated previously [8], the results of this study suggest ways to enhance its quality.

\subsubsection{Assess all skills based on the same problem situation}

This would mean developing a pedagogical evaluation system that allows different skills to be evaluated using the same problem situation. It is important that the problem situation be representative of the patient's daily life, that it is challenging for the patient [17], and not routine. An example for cystic fibrosis might be: having to deal with a flare-up while on vacation.

The proposed improvements are aimed particularly at adaptation to illness skills (self-image, self-efficacy, and life plan), which have thus far been assessed in only a general way, and not in connection with a particular problem situation. Self-efficacy assessment is aimed primarily at exploring the patient's locus of control with respect to the disease [19], that is, his belief that his actions influence (or not) the results - in particular, the course of his illness. This aspect of self-efficacy is still difficult to assess, and is especially difficult to change through patient education alone. It therefore seems more pertinent to assess the sense of personal self-efficacy - still called by some authors the "perceived competence" [20,21]. Indeed, one study with diabetic patients showed correlations between glucose control and the perceived competence, evaluated using a validated questionnaire (the PCS, or Perceived Competence Scale) [22]. We therefore need to assess the patient's perception of his ability to use his skills in a given situation by asking him to rate himself between two extremes - for example, between "I don't have any confidence in my ability to manage a flare-up in this context" and "I have complete confidence in my ability to manage a flare-up in this context". Similarly, we might ask the patient to describe his image of himself (or his perception of how others see him) within the context of solving the same problem situation.

Regarding procedural skill, some authors have proposed questionnaires assessing the quality of its implementation in a given period of time. The goal is to determine the risks associated with practices of insufficient quality [23]. While this type of data can be useful, we feel it important, with the proposed pedagogical evaluation system, to continue to observe the procedure whenever possible in the evaluation situation. Indeed, there are differences between what patients might say about a procedure and the way they actually perform it [24]. When 
it is impossible to have the patient perform the procedure, we can use a past situation in which the patient had to perform the procedure in order to better approximate how it is performed in a problem situation. By using explicitation techniques, the patient is asked to recall a past situation, and is helped to describe the different stages of his action [25]. The result obtained in this way better reflects the actual performance of the procedural skill than traditional evaluation tools do.

Together, these improvements would help make the evaluation more "authentic" [26]. The authentic assessment includes contextualized tasks that apply to complex problem situations, in which self-assessment plays an important role.

\subsubsection{Keep the measurement scales simple}

The fact that most of the scales offer a small range of variability might limit the statistical analysis. We deal with this limitation by using nonparametric tests, which are well-suited to this type of data. Moreover, by performing the skills evaluation system three times, we are able to test the stability of the associations, which is a reliability criterion for the results. Increasing the number of levels on the rating scale would require precisely defining all of the levels so that they could be distinguished from one another. We believe that it is important to keep the four-point scale for assessing self-care and metacognitive skills; it was originally chosen for its simplicity, and in the interest of validity and objectivity each level was described using precise indicators [3]. It is still important to have a pedagogical evaluation system that can be easily adapted by education professionals, so that they can create a formative evaluation activity in a reasonable amount of time. However, when patients achieve a high level of skill, caregivers have to design and use more precise evaluation tools that permit detection of very small changes in these same skills. This is the case, for example, when evaluating the degree of certainty [10].

\subsubsection{Support the patient's ability to formulate a life plan}

Once the pedagogical evaluation system is oriented toward a single problem situation, it becomes more difficult to evaluate the patient's ability to develop a life plan in connection with that problem situation. The patient's life plan or plans involve a large number of situations for which they will need to manage their disease and treatment.

However, since evaluating a life plan was considered useful by $60 \%$ of patients $(n=48)$ questioned in an earlier study [8], we suggest not evaluating the life plan, as such, but rather talking with the patient about its formulation and accomplishment at the end of the evaluation. This conversation would be based on the evaluation results for the skills needed to implement the life plan, and on identifying other types of resources needed for its accomplishment. In our opinion, this link between evaluating the patient's skills, utilizing the results, and discussing the patient's life plan would be the methodological actualization of the transition from evaluation to a new diagnostic approach to patient education [27].

\section{Conclusion}

This study helps confirm the value of devoting a specific amount of time to pedagogical evaluation, thus providing both healthcare professionals and patients detailed feedback on the patient's progress during a patient education program. It identifies a number of correlations in how these skills change over time, thus highlighting the importance of assessing different categories of skills at the same time - specifically, self-care, adaptation to illness, and metacognitive skills. In this way, the evaluation provides a more comprehensive view of patient acquisition or development. Improvements suggested to increase the quality of the pedagogical evaluation system are based on the potential value of assessing these skills using a single problem situation, thus rendering the evaluation even more contextual and thus more authentic [26]. Additional correlational studies would help confirm the interdependence between skills, making it possible to extend the use of this pedagogical evaluation system to patients with other chronic diseases at different stages of treatment and to assess the outcome of therapeutic education programs.

Conflict of interest: None.

\section{References}

1. HAS-INPES (2007). Structuration d'un programme d'éducation thérapeutique du patient dans le champ des maladies chroniques. Guide méthodologique, INPES; 2007; p. 53-63.

2. David V, Iguenane J, Ravilly S, et al., L'éducation thérapeutique dans la mucoviscidose : quelles competences pour le patient? Rev Mal Respir 2007; 24:57-62.

3. Gagnayre R, Marchand C, Pinosa C, Brun MF, Billot D, Iguenane J. Approche conceptuelle d'un dispositif d'évaluation pédagogique du patient. Pédagogie Médicale 2006; 7:31-42.

4. McCaleb A, Edgil A. Self-concept and self-care practices of healthy adolescents. J. Pediatr. Nurs. 1994; 9:233-238.

5. Parcel GS, Swank PR, Mariotto MJ, et al. Self-managment of cystic fibrosis : a structural model for educational and behavioral variables. Soc Sci med 1994; 38:1307-1315.

6. Flavell J.H. Metacognitive aspects of problem-solving. In L.B. Resnick (Ed.), Perspectives on the development of memory and cognition. Hillsdale: Lawrence Erlbaum Associates 1976 : p. 231-235.

7. Messick $\mathrm{S}$. The once and future issues of validity : assessing the meaning and consequences of measurement. In : Test validity. New Jersey. LEA Publisher 1988; p. 33-46.

8. Marchand C, Iguenane J, David V, Kerbrat M, Gagnayre R. Perception d'utilité par les patients et les soignants d'un dispositif d'évaluation pédagogique centre sur le développement des compétences des patients : une étude exploratoire. Pédagogie Médicale 2010; 11:19-35.

9. Bruttomesso D, Gagnayre R, Leclercq D, Crazzolara D, Busata $\mathrm{E}$, d'Ivernois JF, et al. The use of degrees of certainty to evaluate knowledge. Patient Educ Couns 2003; 51:29-37.

10. Leclercq D. La connaissance partielle chez le patient : pourquoi et comment la mesurer. Educ Ther Patient/Ther Patient Educ 2009; 1(2):S201-S212. 
11. Conway SP, Pond MN, Watson A, Hamnett T. Knowledge of adult patients with cystic firbosis about their illness. Thorax 1996; 51:34-38.

12. David V, Berville C, Verstraete M, Marchand C, Iguenane J, Ravilly S. Patient education for children with cystic fibrosis: feasibility and proposal of a specific longitudinal educational pathway including group session. Educ Ther Patient/Ther Patient Educ 2010; 2(2):S133-S137.

13. Lafortune L, Deaudelin C. Accompagnement socioconstructiviste. Pour s'approprier une réforme en éducation. Presses de l’Université du Québec; 2001.

14. Schön DA. The reflective practitioner: how professionals think in action, Aldershot; 1996.

15. Dory V, de Foy T, Degryse J. L'auto-évaluation : postulat préalable, finalité de la mission éducative ou utopie pédagogique ? Clarifications concerptuelles et pistes pour une application en écucation médicale. Pédagogie Médicale 2009; 10:41-53.

16. Johnston-Brooks CH. Lewis MA. Garg S. Self-efficacy impacts self-care and HbA1c in young adults with Type I diabetes. Psychosom. Med. 2002; 64:43-51.

17. Scallon G. L'évaluation des apprentissages dans une approche par compétences. DeBoeck; 2009.

18. Videau $\mathrm{S}$. Recueil de pratiques visant à harmonises les évaluations pédagogiques des compétences de soins chez les enfants de 9-11 ans en surpoids ou obèses. Educ Ther Pat/Ther Patient Educ 2010; 2(1):15-24.

19. Rotter JB. Social Learning and clinical psychology. New York: Prentice-Hall; 1954.

20. Deci EL, Ryan RM. The empirical exploration of intrinsic motivational processes. Advances in Exp. Soc. Psychol. 1980; 13:39-80.

21. Bandura A. Self-Efficacy mechanisms in human agency. Am. Psychol. 1982; 37:122-147.

22. Williams, GC, Freedman ZR, Deci EL. Supporting autonomy to motivate glucose control in patients with diabetes. Diabetes Care 1998; 21:1644-1651.

23. Stoove MA, Fry C. The Blood Borne Virus Transmission Risk Assessment Questionnaire - Short Version (BBV-TRAQ-SV) Administration and Procedure Manual. Fitzroy, Victoria: Turning Point Alcohol and Drug Center Inc., 2006.

24. Meirieu P. La Pédagogie entre le dire et le faire -1- Le courage des commencements, Paris: ESF éditeur; 1995.

25. Vermersch P. L'entretien d'explicitation en formation initiale et continue. Paris: ESF; 1994.

26. Wiggins, G. A true test: toward more authentic and equitable assessment, Phi Delta Kappa 1989; 70:703-714.

27. Ivernois (d') JF, Gagnayre R. Apprendre à éduquer le patient, Approche pédagogique. 3e ed. Paris: Maloine; 2008. 